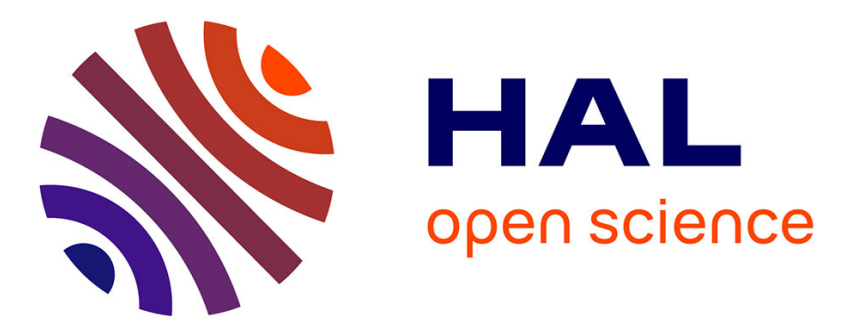

\title{
Interpretation of lidar depolarization measurements of the Pinatubo stratospheric aerosol layer during EASOE
}

C. Flesia, A. Mugnai, Y. Emery, Sophie Godin, L. De Schoulepnikoff, Valentin Mitev

\section{- To cite this version:}

C. Flesia, A. Mugnai, Y. Emery, Sophie Godin, L. De Schoulepnikoff, et al.. Interpretation of lidar depolarization measurements of the Pinatubo stratospheric aerosol layer during EASOE. Geophysical Research Letters, 1994, 21 (13), pp.1443-1446. 10.1029/93GL02897 . insu-03083132

HAL Id: insu-03083132

https://hal-insu.archives-ouvertes.fr/insu-03083132

Submitted on 3 Feb 2021

HAL is a multi-disciplinary open access archive for the deposit and dissemination of scientific research documents, whether they are published or not. The documents may come from teaching and research institutions in France or abroad, or from public or private research centers.
L'archive ouverte pluridisciplinaire HAL, est destinée au dépôt et à la diffusion de documents scientifiques de niveau recherche, publiés ou non, émanant des établissements d'enseignement et de recherche français ou étrangers, des laboratoires publics ou privés. 


\title{
Interpretation of lidar depolarization measurements of the Pinatubo stratospheric aerosol layer during EASOE
}

\author{
C. Flesia, ${ }^{1}$ A. Mugnai, ${ }^{2}$ Y. Emery, ${ }^{1}$ S. Godin, ${ }^{3}$ L. de Schoulepnikoff, ${ }^{4}$ and \\ V. Mitev ${ }^{4}$
}

\begin{abstract}
During the EASOE campaign in the Arctic, all lidar measurements showed total depolarization values for the Pinatubo stratospheric aerosol layer varying between $2 \%$ and $4 \%$. If multiple scattering is negligible, the radiation backscattered by a polydispersion of spheres has the same polarization as the incident light. There is always some depolarization of a lidar return because of the anisotropy of the polarizability of the air molecules, but depolarization in the signal returned from aerosols indicates the presence of non-spherical particles. In this paper, we utilize scattering calculations for non-spherical particles to explore interpretations of lidar signals returned by Pinatubo aerosols. Taking into account several particle shapes and lognormal size distributions, calculations show that only slightly-to-moderate deformed spheres with equivalentmean-radius less then $0.2 \mu \mathrm{m}$ yield depolarization values in the range given by the lidar measurements, if such particles form a substantial fraction of the population. The implications of particle non-sphericity on the retrieval of the aerosol size distribution are discussed.
\end{abstract}

\section{Introduction}

Since the eruption of Mt. Pinatubo led to a large increase of the aerosol loading of the stratosphere, it was possible to observe some features that usually have a small effect on the scattering properties of the stratospheric air parcels. This is the case of particle nonsphericity, which is difficult to observe under normal stratospheric conditions because depolarization of the lidar signal by non-spherical aerosol particles is obscured by that due to air molecules and instrumental effects. The lidar measurements made in the Arctic during EASOE typically show total depolarization values between $2 \%$ and $4 \%$ in the lower stratosphere [Stefanutti et al., this issue], significantly greater than can be explained by molecular scattering, which contributes within $1.4 \%$, while the aerosol contribution is about 1 $3 \%$ [Stefanutti, private communication]. We have used a set of calculations for non-spherical particles made previously [Flesia et al., 1993], to explore interpretations of the depolarization values. Calculated values of

\footnotetext{
${ }^{1}$ Federal Institute Of Technology, Lausanne, Switzerland

${ }^{2}$ CNR, Istituto di Fisica dell'Atmosfera, Frascati, Italy

${ }^{3}$ Service d'Aéronomie CNRS, Université Pierre et Marie Curie, Paris, France

${ }^{4}$ Observatoire Cantonal, Neuchâtel, Switzerland
}

\section{Copyright 1994 by the American Geophysical Union.}

the depolarization ratio for radiation backscattered by polydispersions of non-spherical particles, and by mixed polydispersions of spherical and non-spherical particles, are shown. Multi-wavelength lidar returns have been used to derive the parameters of log-normal distributions, assuming that these contain various mixtures of spherical and non-spherical particles. To illustrate the effect of non-sphericity on the retrieval of ozone concentration, we have used these parameters to calculate Angstrom coefficients and extinction-to-backscattering ratio, and have compared these quantities with the corresponding ones for distributions of spherical particles retrieved from the same lidar signal.

\section{Interpretation of lidar depolarization measurements}

Depolarization lidar measurements permit the computation of both the backscattering ratio and the depolarization ratio $(\delta)$ (defined as the ratio of the backscattered power in the cross-polarization plane to the backscattered power in the polarization plane) of the laser beam induced by the atmospheric constituents. Assuming that molecular scattering can be evaluated with a high degree of accuracy, the aerosol depolarization ratio $\left(\delta_{u}\right)$ can be obtained from the measured depolarization and backscattering ratios [see, for instance, Stefanutti et al., 1991]. We compare measured values of the aerosol depolarization ratio with values calculated for polydisperse mixtures of randomly-orientated non-spherical particles with refractive index $(n)$ in the range $1.40-1.48$. (A polydisperse mixture is an ensemble of particles having different radii and shapes.) We have assumed normalized log-normal size distributions, which are given by:

$$
P(r)=\frac{1}{r \ln (s) \sqrt{2 \pi}} \exp \left[-\frac{1}{2}\left(\frac{\ln \left(\frac{r}{\eta}\right)}{\ln (s)}\right)^{2}\right]
$$

where $\eta$ is the median radius, and $\mathrm{s}$ the dimensionless geometrical standard deviation. We prefer, however, to express the log-normal by means of the mean radius $\bar{r}$ and the standard deviation $\sigma$ (note that $\sigma$ has length units). The correspondence among these parameters is given by

$$
\begin{aligned}
\bar{r} & =\eta \exp \left(\frac{s^{2}}{2}\right) \\
\sigma & =\eta \exp \left(\frac{s^{2}}{2}\right) \sqrt{\exp \left(s^{2}\right)-1}
\end{aligned}
$$

The generalization to multi-mode log-normal size distribution is straightforward.

The scattering calculations for non-spherical particles have been carried out using a numerical code based on the Extended Boundary Condition Method (EBCM), described by Mugnai and Wiscombe [1986]. The ef- 
fects due to particle shape have been analyzed in detail by considering mixtures of elongated particles and mixtures of particles which can be obtained by continuously deforming a sphere. In the first case, we have used prolate spheroids with axial ratios (elongations) $e=1.05$ to 3.30 , in steps of 0.05 . In the second case, the so-called Chebyshev particles [see Mugnai and Wiscombe, 1986], which are obtained by rotating the curve $r(\theta)=r_{0}\left[1+\epsilon T_{m}(\cos \theta)\right]$ about the axis $\theta=0$; here, $r_{0}$ is the radius of the unperturbed sphere, $\epsilon(|\epsilon|<1)$ is the deformation parameter, $T_{m}(\cos \theta)=\cos (m \theta)$ is the Chebysher polynomial of degree $m$. In this study, we have considered Chebyshev particles with waviness parameter $m=2,4,6,8$ and deformation parameter $\epsilon=-0.3$ to 0.3 in steps of 0.01 . A three-dimensional representation of $T_{m}$ shapes can be found in Mugnai and Wiscombe [1986]. The characteristics of these particles can be found in a previous publication together with a detailed analysis of their scattering properties [Flesia et al, 1993]. In what follows, in order to compare the results for elongated particles and deformed spheres, we have introduced a deformation parameter $\epsilon$ for the elongated particles as well, by means of the relation $\epsilon=(e-1) /(e+1)$.

It is well known that injection of sulfur vapors in the stratosphere results in sulfate aerosols [Turco et $\mathrm{al}$., 1983]. The refractive index of the solution of $\mathrm{H}_{2} \mathrm{SO}_{4} / \mathrm{H}_{2} \mathrm{O}$ liquid droplets depends on the sulfuric acid concentration, which is a function of the ambient temperature and humidity. In the stratosphere, for temperatures between 190-210 $\mathrm{K}$ and water vapor contents of about 4-5 ppmv, the dilution of sulfuric acid is estimated to be between 30 and $70 \%$ [Steele and Hamill, 1981]. For the wavelengths considered in this study $(\lambda=0.308$, $0.355,0.532,0.750$, and $0.850 \mu \mathrm{m}$ ), the corresponding values of the refractive index for liquid droplets are in the range $n=1.40$ to 1.48 [Palmer and Williams, 1975]. Figure 1 shows the dependence of the aerosol depolarization ratio $\delta_{a}$ at $\lambda=0.532 \mu \mathrm{m}$ on the refractive index, as a function of the equal-volume-sphere radius $r_{e v}$ between 0.05 and $0.3 \mu \mathrm{m}$, for mixtures of elongated particles (left panel) and of deformed spheres (right panel). In general, $\delta_{a}$ increases when particle size and/or refractive index increases. In addition, $\delta_{a}$ for deformed spheres is significantly lower than for elongated particles. The variation with size is considerable - for elongated particles, $\delta_{a}$ increases from less than $1 \%$ to about $20 \%$ when $r_{e v}$ increases from $0.05 \mu \mathrm{m}$ to 0.3 $\mu \mathrm{m}$; for deformed spheres, from about $0.2 \%$ to about $7 \%$. In contrast, the variation of $\delta_{a}$ with refractive index, which is negligible below about $0.1 \mu \mathrm{m}$, does not exceed about $2 \%$ and $5 \%$ for deformed spheres and

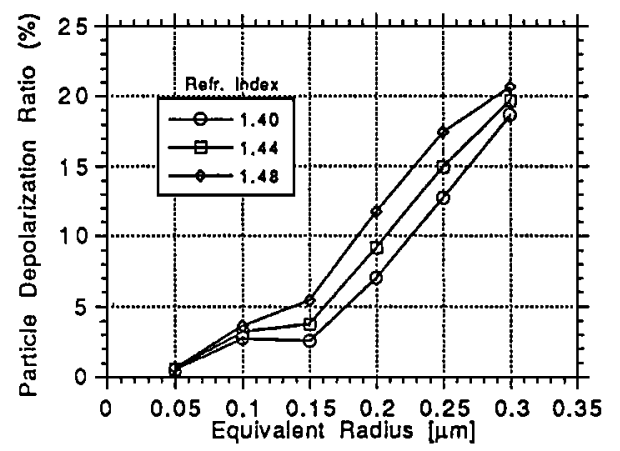

for elongated particles, respectively. We note, however, that this variation may be significant due to the corresponding low $\delta_{\alpha}$ values, especially in the size range from 0.1 to $0.25 \mu \mathrm{m}$.

Scattering calculations for polydisperse mixtures of nonspherical particles are extremely lengthy and have been performed in detail for a single value, 1.40 , of the refractive index. According to Figure 1, we would expect that polydispersions of non-spherical particles having a refractive index as large as 1.48 at $\lambda=0.532 \mu \mathrm{m}$ would show an increase of $\delta_{\alpha}$ of about $1 \%$ for deformed spheres and of about $5 \%$ for elongated particles. At longer wavelengths, this increase would be smaller due to the reduced optical size of the particles.

According to recent in situ measurements [Deshler et al., 1992,1993], the typical size distribution for the Pinatubo aerosol appears to be a log-normal distribution centered around $0.1 \mu \mathrm{m}$ and with a standard deviation $\sigma=0.08$ $\mu \mathrm{m}$. A second mode centered around $0.5 \mu \mathrm{m}$ appears at some altitude levels. These values have been calculated from the measured scattered radiation at an angle $\theta=40^{\circ}$ assuming spherical particles. Nevertheless, we shall use these values for nonspherical particles as well, because at this scattering angle the nonsphericalsplerical intensity difference is rather small - less then $1 \%$ for randomly oriented deformed spheres [Mugnai and Wiscombe, 1989]. Thus, in what follows, we shall consider as a typical base for our calculations six different size distributions measured by Deshler [private communication; see also Deshler et al., 1993] on February 4 for the Pinatubo layer at six altitudes between 13 and $20 \mathrm{Km}$.

Figure 2 shows the calculated aerosol depolarization ratio $\delta_{c}$ at $\lambda=0.532 \mu \mathrm{m}$ as a function of the deformation parameter $\epsilon$ for polydisperse mixtures of elongated particles (left panel) and of deformed spheres (right panel) having size distributions which are those measured by Deshler at six altitude levels $(13,15,16,18,19$ and $20 \mathrm{Km}$ ) in the Arctic stratosphere. Results show that elongated particles depolarize the incident radiation considerably more than deformed spleres. For moderate deformations $(5-10 \%)$ such as those expected for small sulfate stratospheric aerosols particles, the panel on the left shows depolarization ratios from 6 $\%$ to more than $40 \%$ depending on altitude and particle elongation. These values do not match observations at any altitude level. However, for deformed spheres the corresponding $\delta_{a}$ values vary from $1 \%$ to $10 \%$. These results are consistent with the measurements. According to Figure 1, these conclusions would not substantially change had we taken a larger value for the refractive index of the particles.

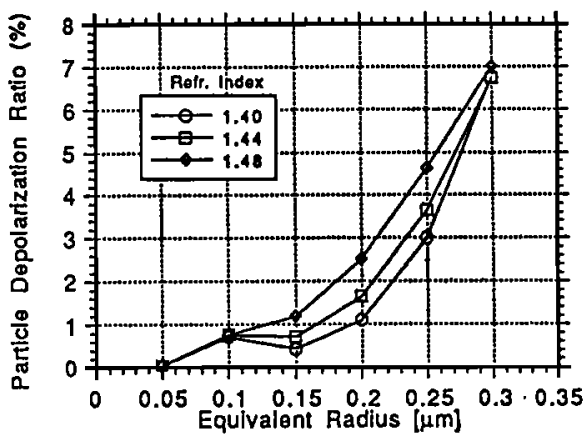

Figure 1. Aerosol depolarization ratio at different refractive indices $(n=1.40,1.44,1.48)$, as a function of the equal-volume-sphere radius $r_{e v}$, for mixtures of elongated particles (left panel) and of deformed spheres (right panel). Wavelength $\lambda$ is $0.532 \mu \mathrm{m}$. 

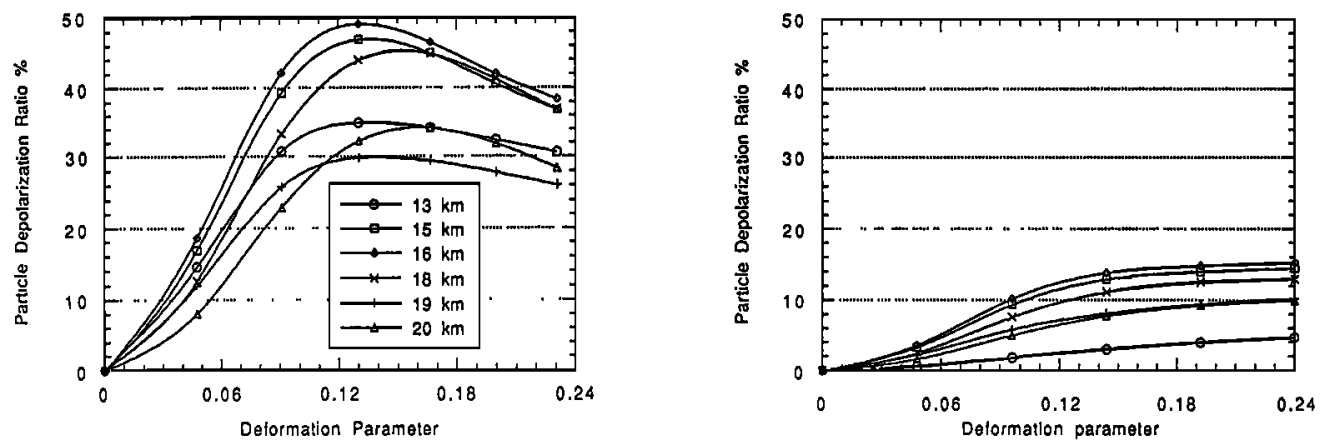

Figure 2. Aerosol depolarization ratio at $\lambda=0.532 \mu \mathrm{m}$ as a function of the deformation parameter $\epsilon$ for polydisperse mixtures of elongated particles (left panel) and of deformed spheres (right panel) having the size distributions measured by Deshler [private communication] at 13,15, 16, 18, 19, and $20 \mathrm{Km}$. of altitude - see text for more details.

Lidar measurements also show larger $\delta_{a}$ values $(2 \%$ to $4 \%$ ) in the lower stratosphere (i.e., up to $15-16 \mathrm{~km}$ ) as compared to the higher altitudes, where an enlianced presence of small liquid sulfuric acid-water droplets with negligible deformation may be the reason why the depolarization ratio decrease to less than $1 \%$. Figure 3 shows the aerosol depolarization ratio at $\lambda=0.532$ $\mu \mathrm{m}$ for polydispersious of particles liaving different percentages of spherical $\mathrm{H}_{2} \mathrm{SO}_{4} / \mathrm{H}_{2} \mathrm{O}$ liquid droplets and non-spherical particles. Results are shown as a function of the standard deviation $\sigma$ for a log-normal size distribution having equal-volume-sphere mean radius $\bar{r}_{c v}=0.1 \mu m$ (i.e., the typical value for the Pinatubo aerosol). The left panel is for elongated particles while the right panel is for deformed spheres. According to the in situ measurements by Deshler, the standard deviation is about $0.08 \mu \mathrm{m}$. Results illustrate that for elongated particles, the measured $\delta_{a}$ values of $2-4 \%$ should correspond to the presence of $10-30 \%$ of nonspherical particles. For deformed spheres, the computed depolarization ratio is compatible with measurements for all spherical/non-spherical mixtures. Again, an increase of the refractive index of the particles would not substantially change the results for deformed spheres; for elongated particles, on the other hand, consistency with measurements would be retained only by further increasing the fraction of spherical particles.

\section{Application to lidar measurements}

Depolarization lidar measurements can be used to retrieve information on the size of non-spherical particles. As an example, Table I shows the mean particle size (i.e., the mean equal-volume-sphere radius $\bar{r}_{c n}$ ) and

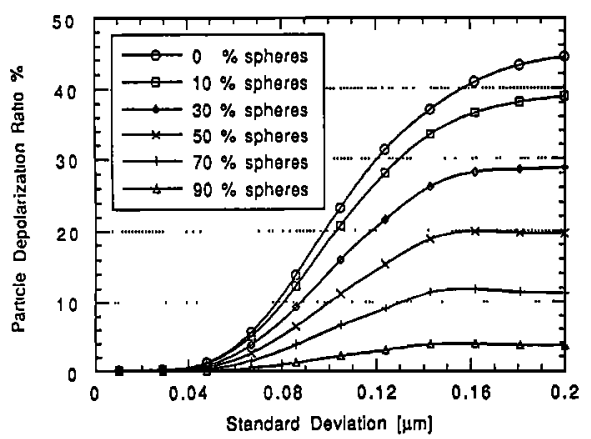

the standard deviation $\sigma$ obtained applying our nonspherical scattering results to the measurements from the multi-wavelength lidar in Sodankyla (Finland) on March 1 at $15 \mathrm{~km}$ lieight. Calculations have been performed by fitting the depolarized lidar signals at three different wavelengths ( $\lambda=0.532,0.750$, and $0.850 \mu \mathrm{m}$ ) with a log-normal distribution of spherical/non-spherical particles and assuming a Rayleigh depolarization of $1.4 \%$. We defined the goodness-of-fit by taking the normalized root mean square residual (Press et al.,1989, chapter 5). The best fit would have a goodness-of-fit of $100 \%$.

The mean aerosol size for elongated particles is smaller than for deformed spheres because of the lower depolarization values of the latter particles. Quite analogously, an increase of the refractive index would systematically decrease the values of the mean particle size.

The values of Table I are smaller than those calculated from the main (parallelely polarized) lidar signals assuming a log-normal size distribution of spherical particles - mean particle radius of $0.78 \mu \mathrm{m}$ and standard deviation $\sigma=0.1 \mu \mathrm{m}$, with a goodness-of-fit of $70 \%$ (remark that it is not possible to reach a goodness-of-fit as good as for non-spherical particles). Our results for corresponding size distributions of non-spherical particles indicate too large values for the depolarization ratio $10 \%$ to $50 \%$ for elongated particles and about $15 \%$ for deformed spheres. However, as the multiple scattering contribution can be neglected, only a non-spherical scattering approach allows a consistent interpretation of lidar depolarization measurements.

The retrieved size distribution can be used to compute the aerosol backscattering $(m)$ and extinction $(p)$

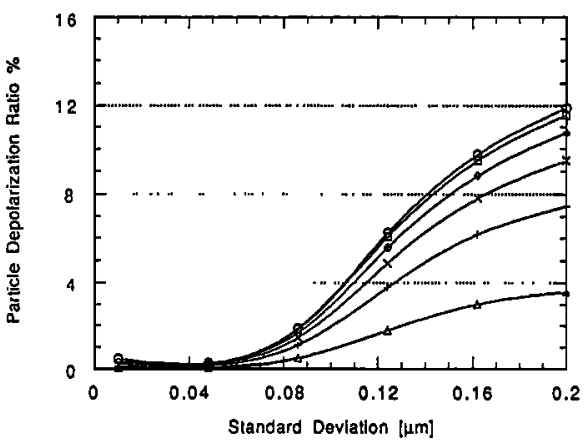

Figure 3. Aerosol depolarization ratio at $\lambda=0.532 \mu \mathrm{m}$ as a function of the standard deviation $\sigma$, for a lognormal size distribution of particles having different percentages of $\mathrm{H}_{2} \mathrm{SO}_{4} / \mathrm{H}_{2} \mathrm{O}$ liquid droplets and non-spherical particles. Left and right panels are for elongated particles and for deformed spheres, respectively. Particle mean radius $\bar{r}_{e \eta}$ is $0.1 \mu \mathrm{m}$. 
Table 1. Retrieval of the size of non-spherical particles from the multi-wavelength lidar in Sodankyla (Finland) on March 1 at $15 \mathrm{~km}$ height.

\begin{tabular}{cccc}
\hline Particle Shape & Mean Radius & Standard Deviation Goodness-Of-Fit \\
& $\mu m$ & $\mu m$ & \% \\
\hline 100\% Elongated Particles & 0.16 & 0.050 & 85 \\
100\% Deformed Spheres & 0.40 & 0.075 & 95 \\
$50 \%$ Elongated Particles + 50\% Spheres & 0.15 & 0.050 & 88 \\
$50 \%$ Deformed Spheres + 50\% Spheres & 0.40 & 0.065 & 93 \\
\hline
\end{tabular}

Refractive index $n=1.40$.

Angstrom coefficients and the aerosol backscatter-toextinction ratio $(\phi)$. Our calculations indicate that although the dependence of $p$ on particle shape is negligible, the eftect of non-sphericity on $m$ and therefore on $\phi$ is considerable. For example, the variation of $m$ due to non-sphericity computed using the size distributions measured by Deshler, would be up to $20 \%$, while the corresponding variation of $\phi$ would be about $12-15 \%$. We emphasize that such variations due to non-sphericity are roughly as large as those related to changes of the size distribution with altitude.

\section{Conclusions}

When interpreting lidar measurements of the stratospheric aerosol layer, the scattering particles are usually assumed to be spherical. However, depolarization lidar measurements taken during the EASOE campaign in the Arctic indicate that non-spherical particles are also present. Our calculations show that the low depolarization values of the lidar signal from the bottom of the Pinatubo layer can be explained assuming polydispersions of slightly-to-moderately deformed spheres lhaving a mean equal-volume-sphere radius of $0.1 \mu \mathrm{m}$ and a standard deviation of $0.08 \mu \mathrm{m}$. Another possible interpretation, which seems to be supported by lidar size distribution retrieval, is the presence of a small fraction (less than 10\%) solid elongated particles with equivalent-volume sphere radii of about $0.1-0.2 \mu \mathrm{m}$ immersed into an aerosol medium of liquid $\mathrm{H}_{2} \mathrm{SO}_{4} / \mathrm{H}_{2} \mathrm{O}$ spherical droplets. The lidar size distribution retrieval assuming spherical particles would produce considerably larger particle sizes incompatible with the measured depolarization ratios.

Finally, we mention that particle non-sphericity is critical for the correction of DIAL ozone measurements from the aerosol interference. To this end, one needs accurate values of the backscattering Angstrom coefficient. However, if we compute this parameter by using the in-situ measurements by Deshler, the variability due to particle shape is comparable to that due to the measured variations of the particle size distribution.

Acknowledgments. This work was partially supported by Swiss Federal Office for Education and Science under project credit No. STEP/EASOE 320-3600.304 and by Programma Nazionale di Ricerche in Antartide of Italy. We would like to thank Dr. Terry Deshler, Dr. Thomas Peter and Dr. Leopoldo Stefanutti for stimulating discussions.

\section{References}

Deshler, T., D.J. Hofmann, B.J. Johnson and W.R. Rozier, Balloonborne measurements of the Pinatubo aerosol sire distribution and volatility at Laramie, Wyoming during the summer of 1991, Geophys. Res. Lett., 19 (2), 199202, 1992.

Deshler, T., Th. Peter, R. Müller and P.J. Crutzen, The lifetime of leewave-induced ice particles in the Artic stratosphere: I Balloonborne observations, Geophys. Res. Lett., this issue, 1994.

Durst, F., A. Melling, J.H. Whitelow, Principles and Practice of Laser-Doppler Anemometry, Academic Press, New York, 1981.

Flesia, C., A. Mugnai, L. de Schoulepnikoff, L. Stefanutti, Lidar depolarization by nonspherical particles: Potential for Polar Stratospheric Clouds characterization, submitted to Appl. Optics.

Mugnai, A, and W.J. Wiscombe, Scattering from nonspherical Chebyshev particles. 1: Cross sections, singlescattering albedo, asymmetry factor, and backscattered fraction, Appl. Opt., 25, 1235-1244, 1986.

Mugnai, A., and W.J. Wiscombe, Scattering from nonspherical Chebysher particles. 3: Variability in angular scattering patterns, Appl. Opt., 28, 3061-3073, 1989.

Palmer, K.F., and D. Williams, Optical constants of sulfuric acid; Application to the clouds of Venus, Appl. Opt., 14 (1), 208-219, 1975.

Press, W.H., B.P.Flannery, S.A.Teukolsky, W.T.Vetterling, Numerical Recipes, Cambridge University Press, 1st edition, 1989.

Steele, H. M., and P. Hamill, Effects of temperature and humidity on the growth and optical properties of sulfuric acid-water droplets in the stratosphere, J. Aerosol Sci., $12(6), 517-528,1981$.

Stefanutti,L., T. Peter, M. Del Guasta, S. Godin, M. Morandi, P. Rairoux, B. Stein, J.P. Wolf, Depolarization lidar returns from the lower stratosphere over sodankyla during EASOE, Geophys. Res. Lett., this issue, 1994.

Stefanutti., L., M. Morandi, M. Del Guasta, S. Godin, G. Megie, J. Brechet and J. Piquard, Polar Stratospheric Cloud observations over the Antarctic continent at Dumont d'Urville, J. Geophys. Res., 96 (12),975-987, 1991.

Turco, R.P., R.C. Whitten and O.B. Toon, Stratospheric aerosols: observation and theory, Rev. Geophys. and Space Phys., 20 (2), 233-279,1982.

C. Flesia, and Y. Emery, Département de Mathématique, Federal Institute Of Technology, CH-1015 Lausanne, Switzerland.

A. Mugnai, CNR, Istituto di Fisica

dell'Atmosfera/CNRS, via Galileo Galilei SNC, I-00044 Frascati, Italy.

S. Godin, Service d'Aéronomie CNRS, Université Pierre et Marie Curie, place Jussieu 4, 75252 Paris CEDEX 05, France.

L. de Schoulepnikoff, and V. Mitev, Observatoire Cantonal, Rue de l'Observatoire 58, CH-2000 Neuchâtel, Switzerland.

(received November 19, 1992; revised April 8, 1993; accepted October 14, 1993.) 